5

\title{
RECORRIDO GENERATIVO DE UN PROYECTO DE INVESTIGACIÓN* DE LOS SIGNIFICADOS AL RELATO, DEL DISCURSO A SU NARRATIVA**
}

"el tiempo se convierte en humano en la medida que se articula a través de un modo narrativo, y la narrativa alcanza todo su sentido cuando se convierte en una condición de la existencia temporal"

Paul Ricoeur

Tiempo y narración

"las narrativas que vivimos tienen tanto un carácter imprevisible como parcialmente teleológico. Si van a continuar siendo inteligibles (...) habrá un sinnúmero de formas en las que puedan continuar"

Alasdair MacIntyre

Después de la virtud

* Publicado en De signos y sentidos. Narrativas de identidad e imaginarios en el discurso teatral rioplatense. Santa Fe: Ediciones UNL. Año 4 / Nº 6 . Año 2007, pp. 5-42.

** Para la teoría semiótica textual que postulan Hjemslev, Greimas, etc., el sentido accede a la significación a través de una "función" o correlación dinámica de dos formas: el contenido y la expresión. Así, como todo objeto (social, cultural, mítico, literario, audiovisual, etc.) de interés semiótico, las "narrativas" que en su transcurso va construyendo un proyecto de investigación pueden ser definidas según sus particulares modos de producción, y las componentes conceptuales y procedimentales que constituyen dicho proceso de significación se irán articulando según determinados "recorridos generativos", constructivos de su sentido. 


\section{DE SIGNOS Y SENTIDOS INVESTIGACIONES SEMIÓTICAS APLICADAS (1987-2008)}

\section{TRAMOS DEL PROYECTO}

> 1987/89: Teatro y posibilidades de la transposición: intertextualidad y reproducción del sentido

1989/90: El acontecimiento teatral y los mecanismos de recepción en la práctica espectacular

1990/91: Modelos didácticos de transposición semiótica y prácticas espectaculares

1992/93: Acontecimientos y estrategias espectaculares en situaciones de enseñanza y aprendizaje (Programa CAI+D 1992: Experiencias interdisciplinarias sobre lenguajes en interacción dinámica texto-contexto)

1994/96: Perspectivas semióticas y aprovechamientos didácticos en interacciones discursivas (Programa CAI+D 1994: Pensamiento, lenguaje y semiosis en las prácticas educativas)

1997/99: Aportes de la semiótica textual a las prácticas discursivas de la historia (Programa CAI+D 1996: Estudios interdisciplinarios de historia social)

2000/04: Sobre semiótica, enseñanza e investigación en humanidades y ciencias sociales (Programa CAI+D 2000: Estudio de las relaciones entre discurso y sociedad)

2005/08: Travesías del sentido: indagaciones narrativas (Programa CAI+D 2005: Lenguajes, discursos y semiosis en las prácticas sociales)

"Las artes del espectáculo en general, y en particular el teatro, han obtenido en los últimos años un lugar de privilegio para la consideración semiótica, debido a la complejidad de sus mecanismos de producción de signos y a la diversidad de los sistemas de significación que integran su práctica. El estado actual de la teorización y los resultados metodológicos obtenidos son, sin embargo, de un evidente retraso con respecto a lo realizado en otras áreas (la poesía y la novelística, por ejemplo, para citar sólo el caso 
de la semiótica literaria), por lo que sólo pueden mencionarse hoy algunos aportes individuales o de conjunto para la consolidación de una (todavía) incipiente semiótica del espectáculo (...) El estado de la cuestión, en lo referido a las indagaciones semióticas del teatro y las restantes artes espectaculares, se ofrece en la actualidad como ejemplo de heterogeneidad de prácticas, con líneas de investigación no siempre confluyentes en tanto se asientan en presupuestos teóricos, epistémicos o metodológicos diversos. El análisis crítico de los problemas existentes demanda en consecuencia un esfuerzo previo de sistematización que, sin invalidar la capacidad operativa de los instrumentos ya adquiridos, promueva a la vez la transferencia de sus resultados hacia dos órdenes caracterizados hoy por la insuficiencia o inexistencia de aportes: el aprovechamiento pedagógico del teatro y de los medios de comunicación; y la (posible) identidad del teatro y las artes del espectáculo santafesino." (Caudana, 1991: 11 - 13)1

Por cierto... desde entonces han pasado ya veinte años... Desde aquellos primeros tiempos del Proyecto de Semiótica en que, junto con Elsa Ghio y Cristina Rivero, nos lanzábamos (con inusual impulso, aunque hubiera alguna experiencia adquirida en el ámbito privado) al "ruedo" de la investigación sistemática en el campo universitario. Con auténtico entusiasmo; con muchísimas ganas e inquietante incertidumbre. Mientras que, en distintas asambleas y no pocas discusiones sustentadas en el Consejo Superior de la UNL, se debatía en aquellos mismos días el tránsito posible de nuestra Escuela Universitaria del Profesorado hacia una Facultad de Formación Docente. Y a la vez que, también con inusitada ansiedad y expectante nerviosismo, nos preparábamos para afrontar el desafío de nuestros primeros concursos regulares de titularización.

Curiosamente. Como solía argumentar Borges, a la realidad le agradan las simetrías y los leves anacronismos... Porque, así como entonces nos interesaban y preocupaban ya las problemáticas del teatro y de la transposición... veinte años después me corresponde prologar este Cuaderno del proyecto, nueva-

\footnotetext{
${ }^{1}$ Las citas anteriores pertenecen a mi "Introducción" al libro Literatura y espectáculo. La transposición, que compila una selección de informes y otros trabajos producidos durante el desarrollo del primer tramo del Proyecto de Semiótica, iniciado en junio de 1987. Dicho volumen colectivo fue editado por el Centro de Publicaciones de la Universidad Nacional del Litoral, Colección Ciencia y Técnica, en octubre de 1991.
} 
mente vinculado con el primer objeto de estudio... y sustentar mi admisión al Doctorado de la UBA, recuperando la segunda cuestión como isotopía principal de su tratamiento temático...

\section{SOBRE EL DECIR O EL CONTAR... EN LA ESCRITURA DE LOS PROCESOS Y ACONTECIMIENTOS DE UNA INVESTIGACIÓN}

"...a través de [la producción de] su narrativa de caso, el científico social se convierte en algo más que un narrador objetivo de experiencias: opera como un filtro narrativo, a través del cual se modela la experiencia y se le da sentido"

Nancy Zeller

La racionalidad narrativa en investigación

En este trabajo pretendo reseñar y articular las principales experiencias (¿por qué no vivencias?) que hemos ido incorporando a lo largo de estos últimos veinte años de investigación, que en particular dedicamos al desenvolvimiento de una línea de indagaciones aplicadas a diversas prácticas semióticas específicas: espectaculares, didácticas, historiográficas, etc. A la vez, procuro dar cuenta de los más importantes aportes o contribuciones efectuadas a través del diseño y desarrollo de distintas etapas del proceso teórico-metodológico recorrido en su transcurso.

No obstante, aunque sin perjuicio de legitimidad o pertinencia de las intenciones planteadas, en el trayecto discursivo que media entre esta enunciación de propósitos y la efectiva concreción de su práctica habrán de establecerse (por fuerza) ciertas comprometidas distancias, y también eventuales disidencias, por lo menos en términos de validez o de presunta objetividad.

Siempre será así. Porque, tal vez por necesaria e inexcusable razón, a través de las siguientes referencias habrán de excederse o desbordarse las fronteras de lo reseñado (sus significados, el contenido mismo de la comunicación pretendida) así como los propios límites de la reseña, en tanto vehículo discursivo o estructura de cauce del relato investigativo.

Quiero decir que, a diferencia de un informe técnico de investigación, casi siempre sumamente preocupado (y de manera singular) por el minucioso re- 
gistro de sus indagaciones, no se tratará tanto aquí de describir los procesos y de presentar sus resultados (esto es, de mostrarlos en términos de validación o cumplimiento de diseños, objetivos, supuestos e hipótesis), como de aproximarnos a ciertos momentos de su historia, del devenir de su proyecto. De enfatizar determinados aspectos de su perfil y de su evolución en tanto propuesta dinámica de una investigación (todavía) en permanente y actualizado desarrollo.

Vale decir que, en lo fundamental, habrá de interesarme detectar ciertas regularidades del proceso de estudio e indagación, las curiosas afinidades y continuidades que, en diferentes instancias de su desenvolvimiento, privilegiaron la trama transdisciplinar e intertextual... por sobre el tratamiento del caso o el ejemplo.

Esto es: las recurrencias, más que las singularidades; las mixturas, los desplazamientos, los cruces y desvíos (así en lo temático, como en lo teórico y metodológico) por sobre las fronteras estrictas y rigurosas que pudieran consagrar las fuentes, algunas referencias conceptuales, ciertas dimensiones analíticas e interpretativas... Es que, en última instancia, esta u otra reseña apenas si procura conformar, en términos de textualidad, el suplemento de un trayecto profesional de vida implicado en su propia enunciación. Porque más allá de los trazos que señala y conserva su escritura (ante tanto relevo de experiencia, de búsqueda no siempre certera o satisfactoria), lo que simplemente resultará siempre es la operatoria sincrética de un conjunto de decantaciones previas. Cuando no la reinstalación de voces silenciadas o (tanto otro) fragmento de escenario: la recuperación de lo dicho en la dinámica misma de su propio decir, reconstituyendo la gráfica estereoscópica de una narrativa...

Transcurrido el tiempo de los hechos y los sucedidos (sin los cuales, no habría narrativa posible), el discurso y la escritura proveen sus propios acontecimientos. Con ellos, la decantación de sus resultados: series de ocurrencias múltiples, ecos simultáneos de lecturas plurales; infinitos matices que fueron construyendo con el tiempo una narrativa de la pasión y las vivencias, que subsume tanto informe circunstanciado por la predicción y el intelecto.

Por cierto: todas plusvalías del sentido. Heterogeneidades constitutivas que (aunque sabemos) definen cualquier situación de enunciación, acá quisieran volverse (valerse, y representarse) también (como) enunciado. Efectos de narración, una vez más, y en definitiva: de nuevo operando en los intersticios 
articulatorios de historia y relato ${ }^{2}$.Aquí aplicados a una narrativa de investigación, inspirada en diferentes registros de narrativas de caso ${ }^{3}$.

Efectos, más que resultados: por esa inveterada necesidad o costumbre de recomenzar, una y otra vez, a "contar el cuento" (desde la minucia, la explicación, el fragmento o el ejemplo... poco importa el cómo); en trance de lúdica ficcionalidad, o a manera de puro y simple desdoblamiento especular del comentario...

Quiero decir: recreando, reconstituyendo en situación de contexto narrativo, el orden y las modalidades propias del relato... en un incesante pretender pasar en limpio la propia historia que nunca (en sentido estricto) acabará de contarse...

\section{LAS PROBLEMÁTICAS DEL ESPECTÁCULO TEATRAL Y EL ABORDAJE SEMIÓTICO DE LA PUESTA EN ESCENA}

Y, como en toda historia (disponible) para ser contada, siempre hubo alguna vez... Una oportunidad puntual, hacia mediados de junio del 87 y desde entonces... Distintos espacios y circunstancias de encuentro: lugares, situaciones, contextos diferentes. Diversidad inicial de intereses, debates y confrontaciones de índole variada (siempre mediadas por la reflexividad y el afecto), innume-

\footnotetext{
2 En el volumen anterior de esta publicación me interesé por definir a las prácticas narrativas como "complejos sistemas de producción significante en los que interactúan y se sincretizan historias, relatos y narraciones (...). Esto es, como un conjunto de acontecimientos propios de determinado contenido (narrativo), pero también como discursos (efectivamente) producidos y a la vez como enunciaciones 'situadas', que actúan de singular manera en sus particulares contextos e intertextualidades específicas." (Caudana, 2007: 8).

${ }^{3}$ Algunas reseñas que ahora incluyo en este capítulo fueron anticipadas en un volumen anterior de la serie Cuadernos del proyecto. Asimismo, al cumplirse diez años de la iniciación del Proyecto de Semiótica, escribí una primera versión de este "relato investigativo" para otra revista universitaria publicada por la UNL. Cfr. al respecto: "El proyecto en perspectiva", en De signos y sentidos, Año 1, No 1, noviembre 2004, p. 40 y sgtes; e "Intervenciones, proyectos y prácticas en el espacio semiótico del dominio sociocultural" (1987-1997), en Revista Estudios Sociales, Año 7, No 13, septiembre de 1997, pp. 167-80.
} 
rables acotamientos y recortes. Hasta el feliz desenlace ${ }^{4}$ y la activa roturación de simientes ${ }^{5}$, en búsqueda intensiva de una cosecha ${ }^{6}$ fecunda.

En 1987 comenzamos a desarrollar este proceso de investigación, con el diseño de un proyecto que originalmente se denominó "Semiótica y pedagogía del espectáculo". Con aquella primera titulación se pretendía explicitar ya la doble orientación (teórica y aplicada) de la actividad en la que nos iniciábamos, además de dar cuenta de una aspiración por integrar en su transcurso diferentes dimensiones de nuestro quehacer universitario: la necesaria retroalimentación entre docencia e investigación, y la transferencia posible del servicio académico a distintos usuarios del medio.

Por un lado, entonces, la preocupación teórica: la investigación centrada en las hoy llamadas artes del espectáculo... El teatro, el cine, la televisión, el video.... un ámbito de indagaciones escasamente consolidado entre nosotros, por lo menos hasta aquellos años (mediados de los '80), sobre todo si se establecían parámetros comparativos con tantos logros obtenidos en otros campos disciplinares de aplicación semiótica (los textos literarios o las artes espaciales, por ejemplo).

Por otro lado, el interés por verificar algunas posibilidades de aprovechamiento pedagógico de sus resultados. Y esto en su doble sentido de transposición metodológica (la investigación semiótica aplicada a las artes del espec-

\footnotetext{
${ }^{4}$ El diseño inicial del proyecto Semiótica y pedagogía del espectáculo, preparado entre los meses de junio y septiembre de 1987, fue progresivamente reformulado a posteriori y enriquecido con diversos aportes y nuevos intereses más o menos homogéneos. A partir de sucesivos ajustes, nuevos objetivos, direccionalidades y denominaciones atribuidas a los tramos anuales subsiguientes, fue inicialmente evaluado y aprobado en diferentes oportunidades por la Comisión Asesora del Área de Investigaciones de la Facultad de Formación Docente (según consta en Res. FaFoDoc No 255/88, 258/89 y 98/90).

${ }^{5}$ Uno de los aspectos esenciales de nuestro proyecto fue, desde su misma iniciación, la incorporación a su Plan de Formación de Recursos Humanos de graduados recientes y alumnos avanzados de diferentes carreras universitarias de grado. Sin embargo, incluso hasta la actualidad, la nota característica continuó siendo la asistencia y participación de jóvenes tesistas, becarios, graduados y alumnas/os de final de carrera.

${ }^{6}$ Numerosas publicaciones, frecuentes intervenciones en congresos y otros eventos, diseño de nuevas cátedras o seminarios de grado y postgrado, participación en diversos cursos de capacitación, actualización o perfeccionamiento docente, y en jornadas de exposición y debate sobre proyectos de investigación, etc. significaron desde entonces actividades propias de la producción del proyecto o sus derivaciones, así como habituales oportunidades de impacto para la difusión y extensión de las principales tareas desarrolladas en su transcurso.
} 
táculo) y de contribución didáctica: aportar a un más efectivo uso o empleo de ciertos medios de comunicación u otros recursos educativos no convencionales, por lo menos no habituales o de insuficiente rentabilidad en cuanto a resultados, en su aplicación a situaciones concretas de enseñanza y de aprendizaje.

A la par de una y otra orientación (la preocupación investigativa/la transposición pedagógica), y persuadidos de la relativa esterilidad de toda elaboración académica desarraigada del contexto en que se inscribe, a partir de los inicios de la indagación hemos procurado referir siempre textos, manifestaciones o prácticas espectaculares de producción local. A partir de lo ya expresado se delimitaron así, en el comienzo mismo del planteamiento investigativo, tres áreas de interés $u$ objetivos direccionales del proyecto que, en síntesis (absolutamente) reductiva, podrían enunciarse del siguiente modo:

> sistematizar lo existente, o efectuar un análisis sincrético de investigaciones en desenvolvimiento, y producir nuevos aportes en orden a la consolidación de la (todavía, entonces) incipiente semiótica del espectáculo;

$>$ producir y transferir conocimientos, a partir de la demarcación de dicho campo de exploraciones, hacia los ámbitos de la reflexión pedagógica y de la práctica de la enseñanza: en particular, orientados al desarrollo de propuestas de mejoramiento didáctico, con sus repercusiones en las metodologías educativas y en los recursos asociados con diferentes manifestaciones espectaculares;

$>$ indagar en la posible identidad del espectáculo y del teatro santafesinos desde una doble perspectiva: sincrónica o descriptiva, pero también diacrónica o evolutiva articulando, en tal caso, avances de las prácticas semiótica e historiográfica.

Tratándose obviamente de un proyecto general de diseño abierto, esta brevísima caracterización inicial se estableció como perfil genérico de una propuesta de indagación a largo plazo, a la que irían aportando sus progresivos avances y resultados distintos tramos parciales del proceso de investigación.

En la primera fase (años 1987/89), por ejemplo, se abordó el problema del entrecruzamiento de los sistemas significantes literario y espectacular: vale decir, las transformaciones (intersemiosis) que se operan en el pasaje de una práctica textual a otra, produciendo y re-produciendo nuevos sentidos. Excedidos los límites que definían géneros y canales en forma excluyente (esto es: 
desbordadas las fronteras que les fueron tradicionales), nos interesó resolver en aquel primer tramo del proyecto los niveles de transposición de una misma materia significante que se inviste en diferentes estructurales textuales ${ }^{7}$.

Así, en lo metodológico, se procedió a analizar la operatoria intertextual que se generaba en una novela y se expandía hacia dos manifestaciones discursivas derivadas: una propuesta teatral y una adaptación televisiva del mismo texto literario ${ }^{8}$. En la segunda fase del proyecto (años 1989/90), la actividad se centró en el análisis del problema de la construcción del acontecimiento teatral, y en los mecanismos o procedimientos de recepción puestos en juego en la práctica espectacular.

Dicho de otro modo: si en la primera etapa del proyecto interesó el abordaje de la problemática transpositiva literatura-espectáculo, en esta segunda se quisieron verificar los procesos de producción y recepción que confluían en la configuración del acontecimiento o evento espectacular (el hecho singular de

\footnotetext{
7 ¿Cómo delimitar la noción de espectacularidad, de teatralidad en ese espacio de entrecruzamientos? ¿Cómo abordar al teatro (y a las artes del espectáculo) desde la actual consideración de las fronteras de los géneros artísticos, en este juego tabular de especificidades e interferencias entre manifestaciones generadoras y prácticas derivadas? Creímos pertinente iniciar nuestra indagación en este punto (no sólo de rigurosa actualidad, entonces, sino también de inquietante problematicidad) y, con la intención de dar respuesta a algunos de estos interrogantes, es que denominamos al tramo inaugural de nuestro trabajo: "El teatro y las posibilidades de la transposición: intertextualidad y re-producción del sentido". Como ya se dijo, en la elaboración de su diseño participamos con Elsa Ghio y Cristina Rivero desde fines del primer semestre del año académico 1987. El mismo fue evaluado y aprobado por la Comisión Evaluadora de Proyectos de la Facultad de Formación Docente en Ciencias de la UNL. La posterior incorporación de graduados y alumnos, prevista en el cronograma de actividades como formación de recursos humanos en iniciación a la investigación, se efectuó por invitación de la conducción del proyecto.

${ }^{8}$ Nos propusimos indagar inicialmente, a partir de las advertencias y posibilidades que nos ofrecía una lectura intertextual de la novela De dioses, hombrecitos y policías de Humberto Constantini (1984) y algunas prácticas espectaculares derivadas (la propuesta escénica del grupo santafesino "Teatro Taller", dirigida por Julio Beltzer, y la adaptación televisiva de la novela para el Ciclo "Ficciones", de Argentina Televisora Color, con dirección de Sergio Renán), los procesos de transformación semiótica (esto es: redundancias, fragmentaciones, amplificaciones, distorsiones, etc.), de resignificación y demás ritualidades que pudieran operarse en dichos pasajes. En consecuencia: nuestro objeto de estudio era establecer, desde la experimentación de las posibilidades y fronteras de los géneros, los eventuales márgenes de discrepancia y de enriquecimiento significativo que pudieran establecerse en las interferencias discursivas, los límites (relativos) de la especificidad, y los procedimientos mediadores para el surgimiento (producción y re-producción) del sentido en dichas transposiciones y contaminaciones.
} 
la puesta en escena). Y de esta manera poder avanzar en su reflexión a través de la observación participante de las sucesivas transformaciones que se ejecutaban en distintos ensayos y montajes, a los que asistíamos periódicamente. Esto es: constatar los indicios de pluralidad, o bien, la constitución del conjunto a partir de lo fragmentario.

Estas propuestas y desarrollos permitieron avizorar, en aquellos momentos, la posible direccionalidad de un tramo subsiguiente, con sus reintegros tanto en lo teórico como en lo metodológico: el nuevo pasaje del acontecimiento (lo único, lo efímero e irrepetible) a lo que provisoriamente se denominó texto espectacular. Vale decir, la construcción del modelo, de una entidad abstracta e hipotética que se conformaría como summa de puestas o representaciones: otra dimensión de lo singular, pero en este caso obtenido por la síntesis y síncresis de pluralidades.

Resumiendo. Los tramos I y II de la todavía incipiente línea investigativa en desarrollo se propusieron, en definitiva, como indagación de estructuras significantes parciales, actuantes en la transposición de obras literarias a textos dramáticos, y de éstos a sus puestas teatrales, en relación con materiales concretos o soportes significativos del sentido textual utilizados en cada montaje (actuación, gestualidad, movimientos, iconografías, etc.). De manera tal que, en tramos posteriores del proceso analítico, la propuesta pudiera ser remontada inductivamente, desde las descripciones de estos sistemas de composición hasta una estructura espectacular que, aunque no fuera (aún) formalizada en un sistema (totalizador), tendiera a representar, siquiera sea en términos provisionales, el esquema significante de las (sucesivas) puestas en cuestión.

El contacto habitual con los integrantes de los grupos "Teatro Taller"9, "Nuestro Teatro"10 (ambos de la ciudad de Santa Fe) y del "Teatro Municipal

\footnotetext{
${ }^{9}$ La actividad se desarrolló, en este segundo caso, a través del trabajo de adaptación y montaje (sobre la novela Aiaiay del santafesino Enrique Butti, por ejemplo), como del análisis de experiencias recogidas en puestas escénicas anteriores de "Teatro Taller" (Anacleto Morones y La loca y el relato del crimen, sobre los cuentos homónimos de Juan Rulfo y Ricardo Piglia, respectivamente).

${ }^{10}$ Asistimos también regularmente a las reuniones y ensayos destinados a la recreación, desde distintos soportes de lo escénico (coreográfico-operístico, inclusive), de la obra teatral Aquella Noche de Corpus, original de Mateo Booz, basada en el suceso histórico santafesino de la Revolución de los Siete Jefes.
} 
de Rafaela"11, la asistencia regular a sus reuniones y ensayos, nos permitieron consolidarnos como equipo de investigación del proyecto y diversificar el corpus inicial de aplicaciones. También, profundizar en el trabajo de campo los supuestos teóricos y operacionales, reorientar la detección de signos identificadores de las series textuales de índole espectacular y, fundamentalmente, intercambiar y enriquecer experiencias y prácticas (con actores, personal técnico y de producción, etc.) a través de las numerosas observaciones participantes que se realizaron durante el seguimiento de los respectivos montajes ${ }^{12}$.

Pero, a la vez que contribuir con algunas aplicaciones o ejercicios prácticos de análisis textual orientados en aquella dirección, nos preocupaba también poder explorar y profundizar en las razones del incipiente estado de desarrollo teórico de la cuestión, recién entonces alcanzado por la semiótica del espectáculo. Y esto, a pesar de la consideración semiótica de privilegio que habían obtenido en aquellos últimos años los diferentes objetos artísticos; quizás (pensábamos), en el caso del teatro al menos, debido a la complejidad de sus mecanismos de producción de signos y a la diversidad de sistemas de significación que integran sus prácticas.

\footnotetext{
${ }^{11}$ En la formulación del nuevo diseño (segundo tramo del proyecto, denominado "El acontecimiento teatral, los mecanismos de recepción en la práctica espectacular y sus potenciales aportes al área pedagógica") se procuraron absorber las experiencias obtenidas en el seguimiento y observación de todas las producciones aludidas. La incorporación al equipo del proyecto de Docentes del Instituto del Profesorado de Rafaela permitió extender la actividad conjunta (con el Grupo Teatral de la Municipalidad de aquella ciudad) a la problemática espectacular radicada en parte del interior de nuestra provincia. Si bien, en este caso, se había previsto en principio la reposición de Adiós, adiós Ludovica del santafesino Lermo R. Balbi, dificultades posteriores motivaron la postergación del inicial proyecto del Grupo Teatral rafaelino y su sustitución por la puesta en escena de Esperando la carroza de Jacobo Langsner.

12 En diferentes textos académicos producidos en esos primeros años informé acerca de los resultados parciales y principales conclusiones del trabajo hasta ese momento desarrollado. Cfr. por ejemplo "Semiótica y pedagogía del espectáculo" (1988) y "Escritura del texto y textualidad de la imagen" (1990), ambos incluidos en Literatura y espectáculo: la transposición. Santa Fe: UNL, Ciencia y Técnica (1991: 9-29 y 181-212). Asimismo, en "El acontecimiento teatral: los mecanismos de recepción en la práctica espectacular" (1991), mímeo. Otros trabajos del período: "Acerca del espacio espectacular y las prácticas pedagógicas" y "Acontecimientos y estrategias en el campo educativo", fueron publicados como artículos de divulgación por la Revista "Orígenes" (respectivamente: Año 2, No 6, diciembre de 1991, y Año 3, No 7, mayo de 1992). También "Algunas reflexiones sobre semiótica y campo cultural" (1993), Enlace Universitario, 3. Universidad Estatal de Bolívar (Ecuador) (1994: 157-170), que fue publicado en Ecuador en oportunidad de desempeñarme como Profesor Visitante.
} 
En su más amplia acepción, las tensiones en su momento existentes entre semiótica y lingüística, la revalorización de la semiosis (en tanto noción y proceso, o sea en tanto problema vinculado con la producción del sentido) y la permanente puesta en discusión de las distintas concepciones de signo..., entre muchas otras razones, seguramente habían incidido en la formulación de modelos heterogéneos que (incluso hoy, aunque con mayor grado de desenvolvimiento) se disputan la prioridad en la atención teórica de las prácticas artísticas en general, no sólo teatrales o espectaculares: la semiótica de la comunicación, de la significación, de la producción significante...

Pero, además ( $y$, quizás, fundamentalmente), en la delimitación de su especificidad y en la compleja articulación de los diversos aspectos involucrados en su misma práctica, residían (así lo seguimos pensando) las principales dificultades que, aún hoy, sigue planteando el análisis del fenómeno espectacular. Y es en esta coincidencia en la que conjuntan casi todos los semiotistas, cualquiera sea el emplazamiento del espectro teórico-metodológico en que se sitúen, y cuyas diferentes propuestas refieren las controversias del campo investigativo o en algún sentido explican la relativa postergación en el avance de su estudio.

Desde los modelos reductivos o formal-estructuralistas, a las modalidades productivas (reconstructivas); sea profundizando en clásicos planteos dicotómicos (texto dramático/hecho escénico, y sus concomitantes: evento-acontecimiento/texto teatral-espectacular, con sus prolijos relevamientos de códigos, categorías y funcionalidades sígnicas, en algunos casos); sea centrando la indagación en la integralidad del objeto y en su polifónica informacionalidad ${ }^{13}$, el itinerario teórico trazado por la profusa bibliografía existente sigue ofreciendo (tanto hoy, como en aquellos años) conflictivos márgenes de discrepancia y áreas de vacancia significativas.

\footnotetext{
${ }^{13}$ R. Barthes definía al teatro, ya en 1963, como una especie de "máquina cibernética" que, en cuanto actúa, emite una serie de mensajes o informaciones simultáneas y sucesivas, si bien de ritmo e intensidad diferentes. En esta verdadera polifonía informacional de la representación (término con el cual Barthes aludía a la pluralidad heterogénea de signos que aquélla emite en un momento dado), en este "espesor de signos" dispuestos en contrapunto, veía el ensayista francés la configuración de la naturaleza esencial del teatro (la teatralidad) por oposición al carácter "monódico" que atribuía entonces al hecho literario. Cf. Ensayos críticos. Barcelona: Seix Barral (1973: 309 - 310).
} 
Sólo aparentemente en un andarivel distinto (teniendo en cuenta las dificultades que supone re-construir el acontecimiento teatral, y habida cuenta de su condición efímera, su singularidad y momentaneidad), proponíamos inscribir la consideración del teatro-espectáculo en una teoría crítica de los medios de comunicación, toda vez que algunas prácticas significantes artísticas como el cine, la televisión y el video proveen asimismo una infraestructura tecnológica, que es la que permite su desmultiplicación, registro y conservación. Coincidíamos entonces con P. Pavis (1986):

"Casi no tiene sentido intentar definir al teatro como un 'arte puro', ni tampoco bosquejar una teoría del teatro que no tenga en cuenta los procedimientos de los medios que bordean y a menudo penetran la práctica escénica contemporánea"; al mismo tiempo que [agrega el mismo autor] la "influencia más profunda de los medios de comunicación [es la de] fundar en la noción de progreso tecnológico y de difusión de masas, toda la reflexión estética" (Pavis, 1986: 25 y 51-52).

Recapitulando: al promediar el tercer año del proyecto se nos insinuaba todavía un encadenamiento de problemas, situaciones y abordajes irresueltos. En síntesis: frecuencia y diversificación de procesos de intercambio entre distintas prácticas significantes; diferentes modos posibles de verificación del complejo sistema de influencias e interferencias virtuales; riesgo determinante de supresiones o limitaciones de las respectivas especificidades genéricas; necesidad de redefinir la dimensión estética (reflexiva y crítica) del arte y los medios en la "era de la reproductibilidad técnica"...

A este repertorio de cuestiones pendientes se sumaban las fecundas posibilidades de aprovechamiento que tales problemáticas generaban en el área pedagógico-didáctica ${ }^{14}$. Unas y otras eran (por cierto, siguen siéndolo) sólo

\footnotetext{
${ }^{14}$ En nuestra primera aproximación al problema ya advertíamos, por ejemplo, que (la incorporación de los medios como recursos didácticos) presuponía el conocimiento de la multiplicidad de códigos y sistemas de significación que de por sí conforman su práctica, además de los complejos mecanismos de producción de sentido que condicionan determinados procesos de percepción y recepción. Simplificando la cuestión, decíamos: la interpretación del qué -del mensaje audiovisual, por ejemplo- es mediada por procedimientos constructivos-deconstructivos del cómo, habitualmente no considerados (o insuficientemente) evaluados en la práctica educativa.
} 
algunas de las motivaciones iniciales que impulsaban la continuidad del Proyecto de Semiótica. Todas ellas, con sus insospechadas derivaciones, nos advertían al mismo tiempo acerca de la necesidad de ir señalando otras aperturas, la conveniencia de proponer nuevas, diferentes exploraciones en el dominio de investigaciones elegido ${ }^{15}$.

\section{EL DISCURSO PEDAGÓGICO, ENTRE SEMIÓTICA Y EDUCACIÓN: ESPECIFICIDAD O PERTINENCIA DE LO ESPECTACULAR}

Nos preocupaba no seguir avanzando sobre los exclusivos supuestos de la diversidad y la heterogeneidad. Sin segmentar o interrumpir el flujo continuo de elementos significantes que parecían definir la especificidad del metadiscurso espectacular ${ }^{16}$, creíamos llegado el momento de establecer una pausa reflexiva y crítica (oportuna, por lo demás, aunque no exenta de riesgo y dificultades) que permitiera recomponer lo decantado y procurara acercar posiciones e integrar planteos no siempre opuestos o necesariamente contradictorios.

${ }^{15}$ La edición (ob.cit.) del volumen Literatura y espectáculo. La transposición quedará, no obstante, como un testimonio de esta etapa introductoria de la biografía del Proyecto de Semiótica. Los trabajos incluidos en aquella publicación respondieron a un criterio previo de selección, establecido sobre la necesaria base de obtener un conjunto homogéneo de estudios referidos de manera explícita a los objetivos de los primeros tramos del proyecto. Incluso, en la mayoría de los casos (cuyos autores eran graduados recientes o alumnos avanzados de carreras de grado), como indagaciones parciales y ejercicios fragmentarios de lectura, en cierto modo documentales de sus primeras experiencias en el hacer investigativo y del estimulante acceso, también reciente, a la posibilidad de su publicación. En cada uno de los artículos de este primer libro se ensayaba una variante indagatoria diferente sobre una misma problemática, constituyéndose (en ciertos casos) en estadios transitorios del procedimiento investigativo o en instancias ensayísticas abiertas, en proceso posterior de reelaboración.

${ }^{16}$ Denominábamos texto espectacular o (directamente) espectáculo -desde la perspectiva de la Lingüística Textual, que concibe al texto como una construcción teórica abstracta (Schmidt) que el analista hace de un discurso, y a éste como su manifestación en una topología espacio-temporal precisa (Van Dijk): evento o acontecimiento al lugar en que se inscribe virtualmente la representación. Dicha construcción hipotética, por su constancia y unicidad, subsume (anuncia y enuncia) las formas (singulares, implícitas) de representaciones efímeras. En tal sentido, coincidiendo con A. Helbo, conveníamos "en llamar texto a todo conjunto organizado (semiótico) que obedezca a las reglas de funcionamiento conectados recíprocamente (... . . Llamaremos estructuras a los recorridos (semánticos) inscriptos en el interior de un texto". Cf. al respecto A. Helbo (1986) "Construir la coherencia. El espectáculo teatral", en Gestos, 2. California-Irvine, p. 31. 
Así, antes de abordar cuestiones explícitamente referidas a la interacción perspectivas semióticas/problemáticas educativas, convinimos en la necesidad de consolidar y profundizar en la fase siguiente (años 1990/91) los resultados obtenidos, y de elaborar algunas propuestas de transferencia, transposición y mejoramiento didáctico, a partir del aprovechamiento de las comprobaciones efectuadas durante aquella primera etapa del proyecto ${ }^{17}$.

Tras la aparente evidencia de lo obvio y habitual, no obstante, lo primero que se imponía a la reflexión, en el nivel de las realizaciones particulares, era la entropía informativa del acto educativo mismo: la complejidad de un suceso en el que permanentemente se recortan e intercambian (combinan, enfrentan, entrecruzan y a menudo yuxtaponen) distintos dominios y formalizaciones del sentido. Esta verdadera polifonía significativa parecía dar suficiente cuenta de lo controvertido del objeto de estudio y del análisis ${ }^{18}$, toda vez que comprometía

${ }^{17}$ La aptitud para decodificar los mecanismos productivos de un evento espectacular, complejidad sistemática compuesta por múltiples códigos y lenguajes, de por sí es transferible a la acción pedagógica de un Profesor de Artes o en Letras. Sin embargo, en nuestro Proyecto (particularmente en sus tramos segundo y -en este- tercero) se procuró abordar de modo explícito sus potenciales aportes al área pedagógica y sus posibilidades didácticas, en orden a la estimulación, el retrabajo o la conclusión de un tema encarado como de resolución multi o interdisciplinaria. Del cuento a la dramatización, de la novela a su dramatización, del lenguaje gestual a la teatralización, de la dramatización a la narración verbal, etc., etc., entre otras tantas posibles, serían algunas aplicaciones didácticas de la intersección de distintos lenguajes, en la configuración de los fenómenos expresivos y comunicativos, las cuales aún siguen requiriendo adecuada y pronta sistematización. Cfr. en especial los diseños de los Subproyectos 1 y 2 del Tramo III del Proyecto de Semiótica (1990/91): "Modelos didácticos de transposición semiótica y prácticas espectaculares", denominados (1) "Matrices textuales de representatividad y programas de operatoria interdiscursiva" (a mi cargo), y (2) "Acontecimiento teatral, acción dramática y aprendizaje: implicaciones y potencialidades operativas" (a cargo de Cristina Rivero), ambos respectivamente articulados con desarrollos y conclusiones anteriores de los Tramos I y II del Proyecto. ${ }^{18}$ Considerábamos necesario además, en tanto proyecto de investigación que se ejecutaba en una Facultad de Formación de Profesores, indagar en los distintos lenguajes y códigos que conforman la producción de nuestro mensaje pedagógico, y también posible establecer analogías entre producción escénica y producción didáctica. El diseño del Subproyecto 3 del tramo indicado en la nota anterior ("Función teatral del discurso docente y estrategias espectaculares en situaciones de enseñanza-aprendizaje") fue posteriormente reelaborado y articulado con el Proyecto "Actitudes lingüísticas y discurso del aula", dirigido por Elsa Ghio, en un mismo Programa de Investigación. De esta manera se dio nuestra primera presentación, en noviembre de 1990, a las (a partir de entonces) periódicas convocatorias de las programaciones CAI+D, en este caso efectuada ante la Secretaría de Investigación Científica y Tecnológica de la Universidad Nacional del Litoral. 
(de nuevo) su particular estructura y caracterización. La posibilidad constructiva, incluso, de un tipo de discurso específico:

> Porque en términos de delimitación, las componentes y modalidades propias del imaginario pedagógico no sólo se manifiestan en contextos exclusivos, generalmente relacionados con la institución escolar, sino también en toda la gama posible de prácticas socioculturales que se generan en situaciones de interlocución y demanda participativa de público o audiencia: desde lo familiar hasta lo político, publicitario, periodístico, jurídico...

$>$ Porque en tanto configuración, no sólo acontece como una estrategia más de la palabra sino que incorpora e integra al orden del lenguaje nuevos soportes o materiales significantes, distintas estructuraciones de los códigos gestuales, quinésicos, proxémicos, paralingüísticos (en general -una vez más-espectaculares), igualmente no específicos de su desenvolvimiento.

Por las mencionadas razones, el propósito del (cuarto) tramo siguiente de la investigación (años 1992/94) ${ }^{19}$ fue desarrollar un posible modelo de análisis semiolingüístico y pragmático del discurso pedagógico: propuesta necesariamente centrada en la heterogeneidad constitutiva y representativa de los procesos discursivos de intercambio y en las estrategias espectaculares que operan en el campo de las situaciones de enseñanza y de aprendizaje, en tanto prácticas situadas en contextos institucionales.

Con este recorte del objeto de estudio, y la consecuente reorientación de la tarea investigativa, el proyecto fue definiendo progresivamente una nueva especificidad: un lugar en el que lo semiótico, lo pedagógico y lo espectacular conjuntan, intersectan, dialogan entre sí (se refieren, aportan y enriquecen

\footnotetext{
${ }^{19}$ Con la denominación de "Acontecimientos y estrategias espectaculares en el campo discursivo de las situaciones de enseñanza-aprendizaje", el cuarto tramo del Proyecto de Semiótica se incorporó al programa de investigación Experiencias interdisciplinarias sobre funcionamiento de los lenguajes en la interacción dinámica texto/contexto, aprobado por la Secretaría de Ciencia y Técnica de la Universidad Nacional del Litoral (CAI+D 91/92), junto con otros proyectos relacionados por un objetivo común: el desarrollo de experiencias interdisciplinarias en torno del funcionamiento de los lenguajes en el ámbito escolar.
} 
simultáneamente). Como se sostenía en los preliminares de su diseño, el nuevo proyecto "parte de caracterizar al conjunto de los 'sucesos' educativos, situados en el contexto de la institución escolar, como prácticas significantes heterogéneas en su constitución y en la representación de sus procesos de intercambio discursivo (en los procesos de producción y recepción de sentido que 'ocurren' en las situaciones escolares). El análisis de tales 'acontecimientos' demanda, en nuestra concepción, la apertura de un espacio reflexivo particular: el 'espectáculo' y sus estrategias, que puede ser abordado a través de aportes teóricos y metodológicos integrados, de procedencia semiótica, lingüística, pragmática, didáctica, etc."20

Además, porque no se tenía conocimiento hasta entonces sobre la existencia de investigaciones proyectadas hacia el establecimiento de posibles analogías entre producción escénica o espectacular y producción didáctica (y muy escasas referencias a la explicación e interpretación de estrategias de intercambio discursivo en el campo pedagógico). Investigaciones que permitieran potenciar avances en el estudio exploratorio, descriptivo y predictivo, y contribuir, de este modo, al mejoramiento de una práctica (educativa) consciente de la espectacularidad que (de todas maneras, o en cualquier caso) despliega... El trabajo diseñado para el cuarto tramo del proyecto general sobre "Semiótica y pedagogía del espectáculo" procuró validar, así, los siguientes supuestos e hipótesis:

> Mejor que especificarse como tipo (particular) de discurso, podría conceptualizarse lo pedagógico como práctica significante, campo discursivo o tipologías de procesos de intercambio, con el objeto de dar satisfactoria cuenta de su complejidad o heterogeneidad constitutiva y representativa.

> Las situaciones de enseñanza y de aprendizaje configuran acontecimientos espectaculares, puestas-en-escena en las cuales los roles actorales aparecen definidos por su función dentro del sistema educativo y el discurso del docente establece el espacio de interactuaciones e interdeterminaciones.

${ }^{20}$ Cfr. también, en mi trabajo "El discurso de las prácticas educativas. Perspectivas de análisis", en Decir, hacer, enseñar. Semiótica y pragmática discursiva. Santa Fe: U.N.Litoral, Centro de Publicaciones. Año 1997. pág. 131. 
$>$ Es posible explicitar los mecanismos discursivos desplegados en el proceso de las prácticas didácticas, estudiar comportamientos y propiedades actorales, determinar proyectos enunciativos y tipos de ritualizaciones emergentes, con el propósito de confrontar variantes estratégicas que posibiliten inferir núcleos invariantes de una matriz textual específica (tal vez identificatoria de una idiosincrasia, quizás propia de nuestro sistema educativo).

En términos de categorización, el diseño de la nueva propuesta se definió, incluso desde sus comienzos, como ensayo de experimentación interdisciplinaria (presuponiendo sus previas articulación, reformulación y transferencia de diversas contribuciones teóricas del campo semiótico, pragmático y lingüístico), tendiente a la investigación de la dinámica espectacular del campo discursivo y al desenvolvimiento de sus estrategias en situaciones concretas de enseñanza y de aprendizaje.

Respecto de su finalidad u objetivo direccional, la actividad encarada se postuló como un posible aporte a la indagación de la matriz textual subyacente en nuestro sistema educativo. En cuanto a sus términos, más o menos inmediatos, se proponía como contribución al esclarecimiento del proceso de producción de la práctica pedagógica y sus presupuestos, y (eventualmente) como formalización de propuestas de mejoramiento didáctico.

Los diferentes desarrollos teóricos e investigativos se formularon a partir de registros de ejemplificaciones obtenidas durante observaciones participantes, las cuales fueron efectuadas en diversas situaciones ocurridas en varias instituciones y niveles del sistema educativo formal santafesino.

La iteración del concepto de representación de (sucesivas/simultáneas) re-presentaciones nos permitía, en cada observación, caracterizar la diversa complejidad del fenómeno observado. A la vez, contextualizar las respectivas circunstancias o condicionamientos de su concreta producción discursiva y de su reconocimiento interpretativo.

El trabajo de campo nos posibilitó en síntesis referir o encuadrar, en un marco teórico-analítico preciso, permanentes juegos e intercambios de roles o programaciones actorales: las más diversas variabilidades de sus efectos de 
sentido, en la constitución de un discurso sobre prácticas habituales de interacción educativa, verificados de manera reiterada en las aulas ${ }^{21}$.

La noción de representación, aplicada al campo pedagógico, no sólo implicaba reconsiderar a las prácticas educativas y al discurso que ellas mismas instauran como algo más que una reserva de contenidos para ser transmitidos/ transpuestos e interpretados... No suponía tampoco superar, simplemente la tradicional concepción (formalista) de la comunicación didáctica, a menudo entendida todavía como establecimiento de relaciones unidireccionales que provocan (que están destinadas a provocar) efectos de sentido previsibles...

La noción de representación pedagógica significaba, a la vez, advertir acerca del carácter polifónico, heterogéneo y dialógico de las situaciones de enseñanza y de aprendizaje... Llamar la atención sobre el entramado de redes de sentido que ellas conforman; así como ponderar su coparticipación en torno de una función (nuclear) específica: el espectáculo, estimado como elemento recurrente y vertebrador, organizador o estructurante del campo educativo y sus diferentes acontecimientos particulares.

Vale decir: la entendíamos como una función específica, como una dimensión espectacular (subyacente, implícita) en todo suceso pedagógico, no sólo por lo que ello implica en términos de despliegue de recursos actorales (por

${ }^{21}$ Informes parciales y finales del trabajo realizado forman parte del volumen conjunto Decir - hacer - enseñar. Semiótica y pragmática discursiva, publicado en 1997 por la UNL en su colección Ciencia y Técnica (ISBN 987508-006-3). En particular, los siguientes capítulos: "Procesos y acontecimientos en la construcción del discurso: las relaciones y condiciones de producción del sentido que se escenifican en el aula", de Susana Ferreyra y Ma. Angeles Fontán (págs. 135-145); "La puesta en escena del aula. Circulaciones de sentido y posibilidades de lectura", de Néstor Fenoglio (pp. 147-156); y "Sobre semiótica y educación. Saberes y dominios de un campo (espectacular) de interacciones", de mi autoría (pp. 157-173). También, en el ensayo sobre El espectáculo docente en el aula de Claudia A. Casabella, que fuera premiado y publicado por el Fondo Editorial de la Municipalidad de Rafaela y la Universidad del Litoral en 1994. Algunos avances de este tramo del proyecto general fueron comunicados en jornadas de investigación, y expuestos en diferentes congresos y otras publicaciones. Entre dichas actividades de extensión y transferencia de resultados, merecen citarse: la intervención en el ciclo "Semiótica, sociedad y cultura", organizado por la Subsecretaría de Cultura de la Provincia de Santa Fe (setiembre de 1991) y el dictado de cursos de actualización y de posgrado, por invitación de la Facultad de Humanidades de la Universidad Nacional de Salta (mayo de 1992), de la Facultad de Ciencias de la Educación de la Universidad Estatal de Bolívar (Ecuador, marzo de 1993), y de otras instituciones educativas del medio: Alianza Francesa de Santa Fe, Institutos Superiores de Profesorado, etc. 
así decirlo: como puesta en escena de una exterioridad), sino también, y quizás fundamentalmente, en tanto índole o naturaleza, o como modalización esencial y constitutiva del (mismo) discurso que construyen sus prácticas...

A propósito de estas señalizaciones, proponíamos transpolar la idea de espectacularidad de su ámbito específico u ordinario de consideración: el espacio ritual, institucionalizado de los montajes que, con mayor o menor grado de referencia ficcional, se construyen en un escenario.

Dicha propuesta se sostenía sobre la base de comprobar que, más que en términos de excepción, el espectáculo se ha(bía) ido transformando en textura cultural ${ }^{22}$, en matriz abarcadora de distintas situaciones de interacción sociocultural en las que participamos cotidianamente, incluidas por supuesto las representaciones que corresponden al campo discursivo de la educación.

Partiendo de esta transpolación conceptual y sus supuestos, consideramos que las actuaciones educativas (así como las espectaculares, en su más extendida acepción) se constituyen en la práctica y es la práctica la que construye su sentido... Conjeturamos, al respecto: qué es el espectáculo... Sino un espacio en el que conjuntan prácticas activas, experimentales (lugares para el hacer) y prácticas teóricas, reconceptualizadoras y críticas (lugares para la reflexión sobre el hacer). Sino la controvertida posibilidad de repensar el devenir, la transposición, la intertextualidad, con improntas de desafío teórico: la fugacidad, la singularidad de lo momentáneo, la unicidad de lo irrepetible... Que, por lo mismo, desborda los convencimientos reduccionistas de la exclusiva inteligibilidad, y penetra en el dominio de las estructuraciones socializadas del placer y las pulsiones ${ }^{23}$

Que, en consecuencia, trabaja u opera comprometiendo la unidad cuerpopensamiento (de los actores) en el doble ejercicio de comprender y de transformar el mundo. Procediendo de tal manera que cada acto de representación se percibe como una alternativa: sólo como una variante entre otras, que permite presentir las otras. Remitir al imaginario sociocultural de las prácticas educativas no supondría entonces, necesariamente, pensar en modelos rígidos o meramente re-productivos de imágenes y conceptos, en un sistema unidi-

\footnotetext{
22 Durand, R. (1982) "Sémiologie et relations dans le champ du spectaculaire", en Degrés, 29, Bruselas

${ }^{23}$ Helbo, A. (1989): Teoría del espectáculo. El paradigma espectacular. Buenos Aires, Galerna.
} 
reccional de referencias: sino en una red o tejido de previsiones y de efectos multiplicadores... En un conjunto de alternativas transformadoras, de selección y combinación (de variabilidades didácticas). Significa pensar, en síntesis, en una organización (espectacular) de (los) posibles (en la práctica de la enseñanza).

“El espectáculo, así en el escenario como fuera de él, en vez de reconocerse (definirse) en absolutas significaciones prexistentes, se constituye en la práctica y es la práctica la que construye su sentido. Planificar, organizar el desarrollo metodológico de una clase es preparar algunas condiciones para que se produzca y reconozca un sentido. Pero conducir la construcción de los aprendizajes, en el acontecimiento (espectacular) de la clase, es dar cuenta del proceso del sentido a construir, a través de lo por decir y (de) mostrar, mediante la participación interactiva de actores/espectadores (...) La noción de espectáculo puede convertirse así en 'organizadora' o vertebradora de las estrategias y representaciones, códigos y sistemas que estructuran e instauran diferentes formas y modalidades de la construcción del sentido en el campo educativo: la comunicación verbal y no verbal en la puesta-en-escena del aula, las prácticas polémicas y contractuales de los actores-en-el-teatro institucional, la implícita dinámica representativa de los roles en el heterogéneo campo-discursivo de la educación, etc." (Caudana, 1997: 169-171)24

\section{PERSPECTIVAS SEMIÓTICAS Y PRÁCTICAS DIDÁCTICAS: INTERACCIONES, NUEVAS TRANSPOSICIONES}

Entonces sí comenzaron a concitarse nuevas interrogantes y planteamientos decisivos... Cómo pensar, por ejemplo, en cuestiones vinculadas con el hacer sistemático de las acciones educativas y sus posibles mejoramientos, situados entre los márgenes de un paradigma cultural como el presente, inspirado por turbulentas complejidades. En tiempos en los que se ha ido desplazando el

\footnotetext{
${ }^{24}$ Las citas pertenecen a mi trabajo "Sobre semiótica y educación. Saberes y dominios...", incorporado a la publicación (1997) Decir-hacer-enseñar. Semiótica y pragmática discursiva. Ob. cit. Respectivamente, pp. 169 y 171.
} 
habitual interés por la multiplicación de las simetrías hacia la fragmentación, la ruptura, la discontinuidad de los saberes... ${ }^{25}$

O, quizás con mayor pertinencia... Cómo reconsiderar las formulaciones actuales de la didáctica, posicionados en una perspectiva polémica y crítica acerca de la enseñanza, y a la vez requeridos por las urgencias de un reordenamiento intelectual que nos habilite para reflexionar, desde la complejidad, a propósito de aquellas implicaciones...

A partir de estos planteos problemáticos, las demarcaciones del diseño original del proyecto de investigación semiótica fueron redefiniendo alcances y nuevas proyecciones. A interesarse por integrar objetos de interés y perspectivas de abordaje relacionadas con la posible especificación de un campo interdisciplinar de indagaciones referidas a la comunicación y la enseñanza.

Mejor dicho: el proyecto no hizo otra cosa que profundizar en sus acotamientos y recortes iniciales, en torno de la construcción de dispositivos textuales y estrategias discursivas relacionadas con la producción y negociación de conocimientos o contenidos-significados, a propósito de las significaciones y sentidos que acontecen y conjuntan en toda práctica educacional... Aquellas primeras dimensiones analíticas e interpretativas del proyecto se ajustaron en orden a desarrollar una propuesta teórico-metodológica vinculante entre semiótica y educación, centrada en las posibilidades de interacción de ambos dominios. Que, en tanto nuevo posicionamiento, pudiera concebirse como una tarea que pretendiera dar cuenta de la heterogénea diversidad constitutiva de su objeto. Y que se hiciera cargo (a la vez) de la doble articulación existente entre práctica semiótica y práctica educativa, cada una (a su vez) entendida como hacer (práctica activa, operacional) y como reflexión sobre el hacer (práctica, teórico-crítica).

Propuesta de interacción capaz, en definitiva, de reelaborar sus modos específicos de participación e intervención en un nuevo campo transdisciplinar. A fin de no atender sólo a lo semiótico como objeto-otro de conocimiento para la didáctica, como saber que solamente facilite su intervención en las diferentes prácticas significantes de cada territorio disciplinar a los que se aplica; sino también de interesarse por el propio acontecimiento didáctico, por las prácticas educativas concretas, como objeto-mismo de reflexión y de análisis para la semiótica.

${ }^{25}$ Schnitman, D. (comp) (1994): Nuevos paradigmas, cultura y subjetividad. Buenos Aires, Paidós. 
¿Cómo articular, operativamente, semiótica y didáctica en un (mismo) dominio interactivo, habida cuenta de la dificultosa constitución (por separado) de los dos ámbitos disciplinares específicos...? ¿En qué lugar de sus formulaciones actuales (la una, como teoría de las significaciones -proyecto en permanente construcción-; la otra, como teoría crítica de la enseñanza -en constante reconceptualización-; las dos, a partir de la consideración de sus prácticas, resignificadas en relación con los contextos socioculturales en que se inscriben)..., podrían involucrarse en un diálogo fructífero para ambas partes, sin desmedro de sus respectivas especificidades? Recortando e intercambiando (a la vez) la controvertida legitimidad de sus saberes y la pertinencia de sus aportes para el mejoramiento de las (respectivas) praxis. Creemos que es en dicho encuadramiento global de las interacciones posibles de ser trazadas en el cuerpo sociocultural, de los entramados semánticos plurales que insinúan o construyen los mismos desarrollos disciplinares (mejor: en los intersticios e intersecciones que se generan entre tales espacios móviles de trans-discursividad), donde el campo de la educación puede ser pensado como un territorio privilegiado para la mirada semiótica: para sus maniobras, descubrimientos y experimentaciones...

Por los diversos componentes y proyecciones del campo de la educación, que remiten tanto a lo escolar-institucional como a las más diferentes manifestaciones de lo educativo-informal; a situaciones prescriptas o programáticas como a distintas actividades espontáneas; desde acontecimientos particulares y concretos hasta la totalidad del proceso educacional (en su conjunto). Pero, esencialmente, por la heterogeneidad constitutiva del fenómeno educativo mismo, cuyo abordaje implica acceder a un entretejido de significaciones dadas en textos y discursos de índole científica y normativa, así como axiológica e ideológica, incluso jurídica y política ${ }^{26}$ que demanda, así como específicos itinerarios de lectura, también interpretaciones y reconocimientos simultáneos e integrados, a la vez.

Porque al hablar de "sistema educativo" no estamos aludiendo a un conjunto de relaciones homogéneas y acumulativas, unisistémicas o unidireccionales, sino a una red funcional de significados y referencias. A un tejido de relaciones/ correlativas de divergente constitución y representación. A un espacio de entrecruzamiento de fuerzas y de efectos de sentido. Por lo que (quizás) sería más

${ }^{26}$ Cf. Rodríguez Illera, J. L. (comp.) (1988): Educación y comunicación. Barcelona, Paidós. 
propio entender lo sistemático-educativo en la acepción de un polisistema ${ }^{27}$, esto es: de un sistema de varios sistemas que intersectan entre sí. La observación de las prácticas, por lo tanto, no sólo deviene reflexión teórica. También permiten relecturas de dichas prácticas, a la luz de tales teorías (al menos debieran favorecerlas) que posibiliten ejecuciones motivadas por elecciones conscientes y voluntarias, éticas y responsables.

“Detrás de las escenas cotidianas más rutinarias y familiares de la actividad educativa se despliegan otros acontecimientos, acciones, conductas, que pueden otorgar a la 'nueva mirada' dimensiones significativas insospechadas, tal vez distintas o diversas de las espontáneamente reconocidas; y movilizar 'nuevas actuaciones' las cuales, si no se pretenden transformadoras, por lo menos puedan resultar de una efectiva toma-de-conciencia o de algún otro tipo de práctica reflexiva y comprometida con su específico hacer" (Caudana, 1997: 169)

Así, los progresivos avances teóricos y las sucesivas comprobaciones efectuadas a través de la práctica investigativa misma fueron ayudándonos a corroborar la hipótesis de que, sin perjuicio de los contenidos particulares que transmite o transpone en las diferentes aplicaciones que posibilita (y que se manifiestan en la superficie del texto de la clase), el discurso didáctico puede ser también pensado y aun formalizado como una organización poli/sistémica: como un ordenamiento multisecuencial de estrategias e intersecciones discursivas de diversa orientación, sentido y constitución, que sostienen los actores del acontecimiento educativo, y cuyas interacciones también producen específicos contenidos diferenciales, a menudo implícitos.

$\mathrm{Y}$, además, que el reconocimiento y análisis de estos procedimientos formales, de tales operatorias constructivo/reconstructivas del sentido y la signifi-

${ }^{27}$ Even-Zohar, I. (1978) Papers in Historical Poetics, Tel Aviv. La Teoría de los Polisistemas irrumpe en el ámbito de los estudios literarios a mediados de los años setenta y se proyecta hacia otros campos del dominio humanístico y social. Cf. al respecto Dimic, M., Even-Zohar, I. y otros (1999) Teoría de los Polisistemas. Madrid, Arco/Libros S.L. A partir de la concepción de la literatura como red de elementos interdependientes, cuya funcionalidad específica sólo se determina en su relación con los demás (elementos), es posible establecer conexiones con la semiótica cultural de Lotman, la teoría empírica de Schmidt, los estudios sobre campo literario de Bourdieu, la noción de sistema de Luhmann, etc. 
cación (puestas en la escena de la clase), resisten por un lado la simplificadora interpretación de lo-evidente, y debieran permitir, por otro, reflexionar sobre cuestiones que (en alguna medida) anteceden al efectivo funcionamiento de las prácticas (concretas) situadas en la institución escolar ${ }^{28}$.

Propondré, a modo de ejemplos, algunos trabajos producidos en la dirección señalada, durante el desarrollo de este nuevo tramo del proyecto. Por un lado, los aportes vinculados con la posible reconceptualización de una teoría curricular, integrada con una teoría institucional:

$>$ los relacionados con la concepción del currículum como constructo, en el doble sentido de elaboración selectiva y de objeto de teoría (vale decir, en tanto forma -y no sustancia- que integra contenido y expresión: como construcción cultural y, a la vez, como modo de organización multisecuencial de las prácticas), pensado en términos de un polisistema capaz de subsumir diferentes estructuraciones específicas, con sus propias referencias y transposiciones;

$>$ los trabajos que, a partir de un enfoque estructural-procesual de la dinámica curricular, procuraron identificar las representaciones del sentido en (por lo menos) tres configuraciones o niveles de la significación textual que denominamos, por su diverso grado de complejidad y progresivo acercamiento a las problemáticas concretas, currículum-diseño / proyecto / acontecimiento;

$>$ relacionados con unos y otros aportes, el análisis de los programas de acción implicados en los procesos de transformación de uno a otro núcleo del desarrollo curricular; las modalizaciones también implícitas de las prácticas de realización (del poder/deber/querer/saber) y de los estados (del ser/estar) adquiridos en cada transposición; las modulaciones actorales de los sucesivos protagonistas actuantes en cada instancia; entre otros aspectos considerados ${ }^{29}$.

\footnotetext{
${ }^{28}$ También expuse algunas de las mencionadas argumentaciones en el primer volumen de esta colección y en otras publicaciones; son aquí recuperadas con la intención de reforzar la consecutividad del relato investigativo. Cfr. por ejemplo (2002) "La semiosis didáctica: constituciones, formatos y soportes", Texturas / Estudios interdisciplinarios sobre el discurso, 2; pp. 33-59; y (2004) "Travesías del sentido: indagaciones narrativas", De signos y sentidos, Año 1, No 1, pp. 8-15.

${ }^{29}$ En la base de estas contribuciones y propuestas se encuentran algunas reflexiones incentivadoras de los ensayos: "Por una semiótica didáctica" de A .J. Greimas y "Campo de maniobras didácticas" de P. Fabbri (Le Bulletin, N 7 , 1979, del Groupe de Recherches Sémio-Linguistiques), reunidos en el volumen Educación y comunicación, ob.cit.
} 
Por otro lado se localizan los trabajos de investigación realizados que, habiendo focalizado inicialmente el análisis del acontecimiento didáctico como caso particular de comunicación participativa, se orientaron al relevamiento de un inventario de cuestiones que hacen a la naturaleza formal de las operaciones de sentido subyacentes a la interacción discursiva. A manera de ejemplo, los siguientes casos: las estrategias de funcionamiento del virtual contrato establecido entre sujeto enunciador y enunciatario, la complejidad constructiva de los objetos de valor a transmitir a través de la negociación didáctica, la diversidad de recorridos pragmáticos e interpretativos inmanentes a la sustanciación de dicho pacto, etc.

Espacio esencialmente dialógico y polémico, concluíamos entonces, el discurso didáctico da cuenta de un pacto de verosimilitud que se instaura entre los sujetos implicados por la existencia misma del discurso... Campo de maniobras y de adjudicaciones, es el lugar de la interpretación y la creencia, de los modos persuasivos y manipulatorios de la transmisión del saber (y de todos sus juegos de provocaciones y seducciones, de simulaciones y astucias)...

Es en este sentido que, creíamos (seguimos creyendo) la investigación educativa puede beneficiarse con los aportes de las perspectivas abiertas por la semiótica y la lingüística actuales, integradas al desarrollo de la teoría y análisis crítico del discurso, y orientadas hacia la comprensión y la interpretación del (de los) texto(s). Asimismo, que las experiencias fundadas en ese contexto teórico-metodológico configurarían espacios privilegiados de intervención para el avance de aquel proyecto trans e inter-disciplinar.

Con este marco general de propuestas conceptuales y procedimentales, y además de continuar desarrollándose a través de los aspectos ya referidos, los resultados obtenidos en los anteriores tramos de la investigación en curso se articularon con un diseño de proyección didáctica para un nuevo proyecto ${ }^{30}$.

En este caso, expresamente direccionado a la indagación de posibles interacciones y mutuos aprovechamientos entre abordajes semióticos y prácticas educativas: posibles de ser transferidos, de manera particular, al dominio de la

\footnotetext{
${ }^{30}$ En sentido estricto, en vez de un nuevo diseño, se trata en realidad de la fase 1994-96 de un mismo proyecto general que, con la denominación de Perspectivas semióticas y aprovechamientos didácticos en diversas interacciones discursivas, fue aprobado como proyecto participante en el Programa CAI+D "Pensamiento, lenguaje y semiosis en las prácticas educativas".
} 
enseñanza y el aprendizaje de algunas disciplinas involucradas en el área (que habitualmente se denomina, en los niveles de formación general y básica) de la comunicación y la expresión.

Haciendo confluir perspectivas semióticas y diferentes líneas de investigación, se han procurado detectar algunas claves para orientar el mejoramiento de la enseñanza y el aprendizaje: esto es, proyectar a la transposición didáctica, desde el dominio de análisis de las interacciones discursivas, diversas aplicaciones al estudio particular de sistemas textuales heterogéneos en su significación constitutiva. Se indagaron, así, en distintas prácticas significantes (escriturales, pictóricas, audiovisuales, televisivas, telemáticas...), sus específicos mecanismos de producción y la pluralidad de códigos intervinientes en la construcción de los respectivos discursos, las características singulares de su recepción y los indicadores pragmáticos implicados en cada uno de dichos procesos ${ }^{31}$.

Previo procesamiento y compatibilización de la diversa información obtenida, se abordaron a posteriori el desarrollo y fundamentación de algunas propuestas (pretendidamente) superadoras de lo existente en las prácticas del aula. Las mismas buscaban fundarse en reconceptualizaciones críticas de algunas tradiciones disciplinares y ciertas rutinas didácticas instauradas, a la vez que procuraban redefinir los alcances del aprendizaje de lo lingüístico y de las diferentes prácticas significantes investigadas, desde un enfoque comunicativo y funcional de su enseñanza.

Considerábamos así que dichas contribuciones al mejoramiento didáctico permitirían dar cuenta de la heterogeneidad del dominio comprensivo y expresivo de los hablantes, aportando al logro efectivo de específicas competencias de uso, verbal y no verbal.

Estas disposiciones, más o menos requeridas para una formación habitual del alumnado en situaciones de escolaridad obligatoria, constituyeron también (en aquel momento) prerrequisitos y aportes fundamentales por su directa implicación en un nuevo encuadramiento normativo de reconversión educativa y transformación curricular.

\footnotetext{
${ }^{31}$ En las componentes descriptivas de estas propuestas, ya se insinuaban los ulteriores aprovechamientos del actual proyecto sobre investigaciones narrativas.
} 
Las actividades desarrolladas, tanto para la formación, capacitación y perfeccionamiento de los recursos humanos del mismo proyecto y de otras instituciones ${ }^{32}$, como para la difusión y extensión de los fines y resultados de los tramos previstos y ejecutados ${ }^{33}$, posibilitaron contextualizar (esto es, retrabajar y a la vez referir) indagaciones en desenvolvimiento, y transferir avances parciales a determinadas situaciones de relativo impacto en el aprovechamiento didáctico.

\section{DE LAS PRÁCTICAS DISCURSIVAS DE LA HISTORIA AL GIRO NARRATIVO EN LAS CIENCIAS SOCIALES}

Procurando consolidar y a la vez extender aportes y resultados obtenidos durante una década de desarrollo del proyecto, en la agenda siguiente ${ }^{34}$ nos propusimos abordar nuevas posibilidades de aprovechamiento teórico-metodológico en relación con determinadas transposiciones del análisis crítico del discurso

\footnotetext{
${ }^{32}$ Citaré, entre otras, el cursado regular de los seminarios de postgrado de la Maestría en Didácticas Específicas de la UNL (cohorte 1996/7), el dictado del curso para graduados sobre "Perspectivas semióticas y lingüísticas: aprovechamientos didácticos" auspiciado por la Red Federal de Formación Docente Continua (RM N 880/95), la participación en el dictado del "Módulo sobre Semiótica" en el Programa de Actualización Académica para Profesores de Profesorados del Ministerio de Educación de la Nación (RM No 343/97) en diferentes jurisdicciones provinciales (Córdoba, Entre Ríos, Corrientes y Chaco), y la intervención en eventos pedagógicos específicos como las "Jornadas sobre Investigación y Enseñanza de la Lengua y la Literatura" realizadas en la Universidad Nacional de Córdoba (Facultad de Filosofía y Humanidades). ${ }^{33}$ Cfr. entre otros trabajos, (1994) "Paradigmas de producción y reconocimiento de los textos: relaciones entre teorías y prácticas", en Lenguajes y prácticas educativas. Santa Fe: Centro de Publicaciones de la UNL; (1995) "Problemáticas y singularidades de la escritura y la lectura (desde un enfoque comunicativo y funcional de la enseñanza de la lengua)", en Actas-Congreso Internacional de Didáctica y Metodología de la lengua materna. Montevideo (Uruguay); y (1996) "Fracturaciones y ordenamientos en la trama plural de las representaciones didácticas", en Anais do III Congresso Internacional Latino-Americano de Semiótica. Sao Paulo (Brasil): Pontificia Universidade Católica. Asimismo, las ponencias presentadas en eventos de años subsiguientes: (1997) "Instauraciones textuales en dominios interactivos de naturaleza y cultura (semiótica y perspectivas sobre aprendizaje)", en el VI Congreso Internacional de Semiótica (IASS-AIS), Guadalajara (México); (1998) "Estereotipia y disfunción en los sentidos de la imagen", en el V Congreso de la Asociación Internacional de Semiótica Visual, Siena (Italia).
} 
y la denominada semiótica textual al territorio historiográfico. Las actividades desarrolladas durante esta nueva fase han partido del supuesto de que, con la constitución de dichas áreas disciplinares demandantes de saberes integrados (semióticos, lingüísticos, pragmáticos...), sería posible:

> enriquecer el abordaje de la compleja dimensión significante del acontecer histórico, a partir de la experiencia codificada;

$>$ delimitar sus principales modos de operar sobre el soporte contextual de los datos; $y$ $>$ tematizar, en diferentes manifestaciones textuales (verbales y no verbales, gráficas, espectaculares...), la materialidad discursiva de determinados procedimientos organizativos de selección e interpretación informativa o documental.

Resignificado así el doble anclaje de lo social en el sentido y del sentido en lo social, sería posible concebir al dominio de la historia (sosteníamos) como un privilegiado ámbito disciplinario de interacciones discursivas, las que podrían operar en diferentes direcciones y virtualizando nuevos aprovechamientos: sea como práctica investigativa de la construcción historiográfica, sea como práctica transpositiva de didácticas específicas en el campo ${ }^{35}$.

Tanto las actividades que correspondieron a esta sexta fase del proyecto general, desarrollada en interacción con otros diseños del Programa CAI+D '96 sobre "Estudios interdisciplinarios de historia social", como las tareas programadas para los dos tramos subsiguientes (la propuesta anterior y la actualmente

\footnotetext{
34 El desenvolvimiento de la sexta fase del proyecto ("Aportes de la semiótica textual a las prácticas discursivas de la historia"), abarcó el período 1997-99 y se definió como propuesta de sistematización e indagación crítica sobre perspectivas semióticas actuales (a su vez articuladas con formulaciones pragmáticas y lingüísticas), con la finalidad de verificar sus posibilidades de aprovechamiento teórico-metodológico y de transferir sus aportes al campo de los estudios históricos y de su didáctica específica.

35 Una efectiva transferencia de dichos aportes y resultados del proyecto fue la incorporación de la "Cátedra de Semiótica" a los estudios de grado de la Carrera de (Profesorado y Licenciatura en) Historia. Aquella primera denominación fue con posterioridad reemplazada por la (más propia y específica) de "Análisis del discurso historiográfico". Algunos años antes ya se había incorporado al plan de estudios regulares de la Carrera de Letras, la Cátedra de "Semiótica General", después de siete cursadas (1993-1999) con diferentes versiones de "Seminarios de Semiótica" que estuvieron a mi cargo, en tanto asignaturas específicas del plan original de nuestra Licenciatura en Letras.
} 
vigente) $)^{36}$, se ejecutaron en forma conjunta con otros proyectos del Centro de Estudios Sociales Interdisciplinarios del Litoral (CESIL), con sede en la Facultad de Humanidades y Ciencias de la Universidad del Litoral.

En la confluencia de avances, contribuciones y aportes de los tres proyectos desarrollados en estos últimos años, se fue fortaleciendo nuestra convicción ${ }^{37} \mathrm{de}$ que, en un contexto de progresiva complejización de los procesos educativos, de demandas de mejoramiento de la calidad de la enseñanza y la producción de los aprendizajes, de urgencias transformadoras de la "realidad concreta" de la escuela, además de proponer y describir situaciones precisas o de impacto práctico más o menos inmediato, se impone generar desarrollos teóricos que apuntalen necesarias reflexiones críticas sobre las prácticas que acontecen en la escena del aula...

Procurando extender (a la vez que consolidar) aquellos aportes, en relación ahora con desenvolvimientos de la perspectiva narratológica aplicada a distintas configuraciones analíticas e interpretativas del campo sociocultural, la agenda de trabajo actual aspira una vez más a desarrollar nuevas posibilidades

\footnotetext{
${ }^{36}$ Más abarcadora, en algún sentido, respecto de las distintas problemáticas de las que se quería dar cuenta, se denominó a la séptima etapa "Sobre semiótica, enseñanza e investigación en humanidades y ciencias sociales", a través de la cual se avanzó en la articulación de aspectos teóricos y metodológicos que tuvieron (finalmente) resolución en el tramo actual del proyecto general: "Travesías del sentido / indagaciones narrativas". El diseño anterior fue evaluado y subsidiado en el marco de la Programación CAI+D 2000: "Estudio de las relaciones entre discurso y sociedad"; el actual, en el contexto del Programa CAI+D 2005: "Lenguajes, discursos y semiosis en las prácticas sociales".

${ }^{37}$ De sus diversas orientaciones y sucesivos aportes formulados en esta misma dirección ha venido dando cuenta buena parte de la producción bibliográfica de los integrantes del Equipo en estos últimos años, hasta llegar a concretar este anhelo de una publicación periódica propia: los "Cuadernos del Proyecto", desde fines del año 2004. Por un lado, a través de diferentes publicaciones en colaboración, con sello editor de la Universidad del Litoral: "Lenguajes y prácticas educativas" (1995) y "Decir, hacer, enseñar. Semiótica y pragmática discursiva" (1997), codirigidas con E. Ghio; diversas ediciones con materiales de educación a distancia y cursos de articulación disciplinar: "Semiótica general. Argumentos, actividades, bibliografía" (2000) y "Semiótica general" (2004) para el Bachillerato Universitario en Letras, "Teoría de la Historia" (2004), "Lectura y escritura de textos académicos" (2004), además de varios trabajos incorporados a los seis volúmenes de "De signos y sentidos" aparecidos en los últimos años. Por otro lado, a través de participaciones individuales en numerosos congresos u otros eventos científicos, y de varias publicaciones del mismo carácter incorporadas en revistas especializadas. Algunas de ellas: "Del hacer de la historiografía: acción, historia y narración en P. Ricoeur" en Hablemos de Historia / 3, "Formas de hacer visible en el arte" en Artinf / 114), o mis trabajos "La semiosis didáctica: constituciones, formatos y soportes" (2002) y "Discursividades, texturas... polémicas en la historia" (2003) aparecidos en Revista Texturas / 2 y 3 respectivamente.
} 
teórico-metodológicas y sus modos de transferencia al campo de la enseñanza, el aprendizaje y la investigación en ciencias humanas y sociales.

Así, en síntesis, en el contexto de sucesivas experiencias, incorporaciones y replanteos acumulados durante el transcurso de todo el proceso de investigación semiodiscursiva llevado a cabo (desde 1987 a la fecha, pero especialmente en los últimos años), se han venido gestando preocupaciones y cuestiones de interés que han ido conformando o definiendo perfiles de un nuevo proyecto de investigación y desarrollo.

Configurando un nuevo espacio de sesgo interdisciplinar en que semiótica, investigación y didáctica procuren armonizar e intercambiar sus saberes y conocimientos, sin desmedro de sus respectivas especificidades, se resolvió abordar la recuperación del pensamiento narrativo que subyace a diversas prácticas significantes, hasta lograr la problematización de un objeto de estudio complejo y heterogéneo: una aproximación poligonal al constructo-relato, mediante la convergencia de diferentes orientaciones teóricas y metodológicas.

De acuerdo con esta perspectiva reconstituyente de la noción de relato (de diégesis, de narración, de narratividad...), el tramo actual del proyecto se propone reconocer, en definitiva, nuevas dimensiones y categorías para el análisis e interpretación de las prácticas de la enseñanza y la investigación en el campo humanístico y social.

Se parte así del supuesto de que dichas entidades analíticas e interpretativas habrán de permitirnos reconceptualizar las singularidades de unas y otras prácticas (la enseñanza / la investigación, en el campo), e indagarlas desde entornos diferentes de los habituales. A la vez, que posibilitaría establecer nuevos contextos de referencia para la reflexión y comprensión de los problemas existentes en uno y otro dominio, y enriquecer la mirada que a menudo se proyecta sobre cada uno de ellos, desde los aportes elaborados en el otro.

Naturalmente. Lo más productivo, variado y enriquecedor de todo este planteamiento teórico y metodológico se estuvo dando en las diferentes indagaciones personales o grupales en permanente desarrollo; cada una de las cuales ha adquirido un diferente grado de avance, continuidad, profundización y adecuación (en lo relacionado con los fines, encuadramientos, objetos de estudio, etc. del proyecto general). Entre otras variables textuales del corpus analítico en construcción, merecen citarse: 
$>$ el trayecto investigativo que recupera la tradición espectacular del proyecto (y tematiza sus avances en el presente número de los Cuadernos): profundiza en las relaciones existentes entre narración y representación en las construcciones del discurso teatral, a la vez que estudia los distintos niveles de intervención receptiva que operan en la constitución de los procesos de la puesta en escena espectacular; $>$ un segundo itinerario aborda el entrecruzamiento de miradas que surgen de la reflexión acerca de las relaciones, influencias, migraciones y transposiciones de / entre cine, teatro y literatura (recuperación de una segunda tradición del proyecto): la ritualidad de estos pasajes supone hoy una narrativa de interferencias y transformaciones que no sólo afectan los contenidos semánticos sino también a las categorías temporales, las instancias enunciativas, etc.;

$>$ otro apela a las relaciones entre relato y discurso documental en la construcción fílmica de la realidad social, sosteniendo un estatuto diferencial, una específica y particular vinculación con la realidad extra-textual, extra-cinematográfica: establecen el valor de lo testimonial en la construcción dialéctica de su entidad discursiva; $>$ relacionado con el anterior (aunque en estado incipiente), el tratamiento de cuestiones teóricas, analíticas y críticas relacionadas con la producción, consumo y aprovechamiento didáctico de los denominados textos fílmicos documentales de divulgación científica, a partir del desmontaje de los itinerarios semionarrativos y discursivos que los constituyen;

$>$ un quinto trayecto (sobre hipermedios educativos, su carácter semiótico complejo, sinérgico y paradigmático en los nuevos procesos de lectoescritura) parte del supuesto de que la utilización de nuevos entornos tecnológicos y textualidades electrónicas modifican las transacciones comunicativas, las actividades de codificación y decodificación textual, e instauran nuevos protocolos de lectura y escritura;

$>$ otro bosqueja, todavía en su etapa propedéutica, una serie de aproximaciones (desde lo anecdótico a lo teórico y proyectual) a la cuestión de las narrativas videoclípticas: su especificidad, su constitución como objeto de estudio materialmente heterogéneo y narrativamente multidimensional, las problemáticas de la interpretación y de las transfiguraciones semiósicas de la canción en videoclip, etc. 
Las indagaciones que se llevan a cabo en los demás recorridos o trayectos del actual diseño de investigación procuran dar cuenta de otras construcciones narrativas que se entrelazan en la constitución del discurso social. Tal el caso, por ejemplo, del:

$>$ abordaje de la construcción textual de las entrevistas, entendidas como formas particulares de narrativa, cuyo principal valor deriva precisamente de la puesta en sentido de una subjetividad que permite acceder al entretejido de relaciones establecidas entre los dos universos (personal y social) existenciales del sujeto;

$>$ reconocimiento de cruces, solapamientos, desvíos o confrontaciones que operan entre pensamiento narrativo y otras constituciones (metateóricas, metanarrativas) de la teoría social, a partir de la discusión de determinados tópicos polémicos en el dominio de los modos de construcción y representación del conocimiento social: la problemática referencial, entre otras;

$>$ anclaje en la consideración y tratamiento del cuerpo, de su historicidad y su entidad representativa (uno de los últimos trayectos incorporados); todo lo cual recoge una tradición multidisciplinaria que rescata la problemática del cuerpo de la anécdota y lo centra como objeto de investigación, para luego exponerlo a una hermenéutica semiótica que permita construir desde allí, una nueva categoría de análisis histórico: las bio-narrativas ${ }^{38}$.

Si se consideran la índole singular de aquel objeto (general) de estudio, y aun los espacios de vacancia que ofrecería un dominio reflexivo como el pretendido (todavía no suficientemente estabilizado o consolidado sobre la cuestión), se comprenderá que no puedan mensurarse a priori o calcularse en términos proyectivos efectos sociales, científicos, económicos, etc. del tramo en ejecución.

El desenvolvimiento de los diferentes trayectos investigativos podrá contribuir (indudablemente) al progreso de la teoría de los discursos sociales, a través de la práctica de enfoques inter y transdisciplinarios, en algunos casos con incipientes desarrollos en nuestro ámbito. Permitirá además esclarecer los

\footnotetext{
${ }^{38}$ Cada uno de los trayectos o recorridos teórico-metodológicos que actualmente se están desarrollando en el marco de nuestro proyecto cuenta con un diferente grado de avance: algunos, con desarrollo incipiente, apenas superaron la etapa del diseño; otros han adquirido (ya) una trayectoria de relativa estabilización en términos de desarrollo investigativo.
} 
presupuestos semióticos que operan en toda práctica educativa, historiográfica, espectacular, audiovisual..., en tanto construcciones de sentido que acontecen en un contexto de conformaciones y circulaciones productivas de determinados saberes del campo social.

La explicitación de mecanismos, estrategias, convenciones y representaciones del imaginario social incidirá, específicamente, en la indagación de la problemática polisistémica del fenómeno. Asimismo, de la contrastación de dimensiones, categorías y conceptos propios de la semiótica textual con las respectivas configuraciones discursivas de las ciencias sociales devendrá una instancia superadora de lo existente, que habrá de convertirse en aporte concreto para las prácticas de la enseñanza, el aprendizaje y la investigación en el área disciplinar.

Es decir: el ejercicio interactivo de permutas e intercambios entre prácticas reflexivas, interpretativas y críticas no sólo permitirá ejemplarizar y expandir una dinámica constructiva, esencial e inherente al desarrollo del pensamiento semiótico. También podrá generar aportes concretos a las prácticas didácticas e investigativas aplicadas (y sólo para citar un caso) al campo audiovisual, favoreciendo así una acabada comprensión de los fenómenos de transposición discursiva y textual.

Considerando ahora la cuestión en términos más amplios, pensamos que los resultados del nuevo diseño del proyecto podrán contribuir al desarrollo de (nuevas) ideas sobre la enseñanza en general (de la enseñanza del campo, en particular), concebida como un fenómeno sociocultural (de singular y compleja naturaleza, socialmente construida), y como una acción intencionada, a la vez global y contextualizada (regida por reglas personales y sociales, y no tanto por leyes científicas).

En consecuencia, dichos aportes tenderían a reconceptualizar cuestiones relativas a la índole epistémica y metodológica, a los fines y objetivos de una investigación educativa anclada (en ciertos casos, al menos) en andamiajes empírico-analíticos, y más bien preocupada (todavía) por explicar las leyes de la eficacia docente. La indagación narrativa propuesta, en síntesis, que parte de la revisión del constructo-relato y se aplica al estudio de (diferentes) casos puntuales, se articula con los presupuestos de una investigación interpretativa y crítica, de corte antipositivista, que procura comprender las conductas y los comportamientos desde los significados (a menudo sobrentendidos) e intencio- 
nes (muchas veces implícitas) de los sujetos (actores) sociales que interaccionan en el ámbito educativo.

La virtual comprobación, finalmente, de que ciertas actividades y efectos narracionales o enunciativos, por ejemplo, podrían operar como principios constructivos de diferenciación estructural entre textualidades diversas, permitiría también fundamentar necesarios deslindes respecto de ciertas extensiones habituales, al dominio audiovisual (por seguir con el mismo caso), de indagaciones efectuadas por la teoría literaria, o a la inversa. Asimismo, establecer distintas bases o criterios para categorizar, reconceptualizar o formalizar nuevas clasificaciones, tipologías, etc ${ }^{39}$.

En síntesis, y para concluir... Lo semiótico como hacer, pero esencialmente como reflexión sobre diversos haceres que interactúan en el campo sociocultural (con sus dificultades e insuficiencias, con algunas de sus audacias y tanteos; también con muchas de sus riquezas y potencialidades). Como proyecto que no cesa de construirse en conjunción con el análisis de diferentes discursos, puede continuar sumando su aporte a aquellos propósitos inaugurales de nuestro Proyecto.

A aquella (y esta) búsqueda paciente de nuevos marcos teóricos, operativos e instrumentales de referencia. Siempre condicionada por impacientes búsquedas de resultados.

En fin: riesgos y desafíos, todos, de toda empresa investigativa, que permanentemente nos resitúa frente a un sistema virtual de preguntas, cuyas posibles respuestas sólo logran hacer efectivos otros, nuevos interrogantes...

39 Una vez más, los resultados parciales obtenidos durante el desarrollo de todas estas indagaciones fueron (y son) expuestos en conferencias, informes y ponencias presentadas en congresos, simposios, encuentros, jornadas y paneles de las respectivas especialidades, y editados en actas u otras publicaciones académicas, incluidas las participaciones en colecciones del mismo Centro de Publicaciones de la Universidad Nacional del Litoral. Se llevaron también a cabo otras tareas de asesoramiento y evaluación, y se dictaron numerosos cursos y seminarios, presenciales o a distancia, en cuyas temáticas se abordaron aspectos concernientes al desenvolvimiento de estas investigaciones. Respecto de la formación de recursos humanos, eje central de las motivaciones iniciales del proyecto, volvieron a cumplimentarse las actividades previstas, con la realización de tesis y dirección de tesistas de grado y postgrado, además de la orientación de becarios, adscriptos y pasantes en tareas específicas de docencia e investigación. 